\title{
APPROXIMATION COMMON FIXED POINT OF ASYMPTOTICALLY QUASI-NONEXPANSIVE-TYPE MAPPINGS BY THE FINITE STEPS ITERATIVE SEQUENCES
}

\author{
JING QUAN, SHIH-SEN CHANG, AND XIAN JUN LONG
}

Received 26 December 2005; Accepted 11 March 2006

The purpose of this paper is to study sufficient and necessary conditions for finite-step iterative sequences with mean errors for a finite family of asymptotically quasi-nonexpansive and type mappings in Banach spaces to converge to a common fixed point. The results presented in this paper improve and extend the recent ones announced by GhostDebnath, Liu, Xu and Noor, Chang, Shahzad et al., Shahzad and Udomene, Chidume et al., and all the others.

Copyright (C) 2006 Jing Quan et al. This is an open access article distributed under the Creative Commons Attribution License, which permits unrestricted use, distribution, and reproduction in any medium, provided the original work is properly cited.

\section{Introduction and preliminaries}

Throughout this paper, we assume that $E$ is a real Banach space, $F(T), D(T)$, and $N$ denote the set of fixed points of $T$, the domain of $T$, and the set of positive integers, respectively.

Definition 1.1. Let $T: D(T)=E \rightarrow E$ be a mapping.

(1) $T$ is said to be quasi-nonexpansive if $F(T) \neq \varnothing$ and $\|T x-p\| \leq\|x-p\|$, for all $x \in E$ and $p \in F(T)$.

(2) $T$ is said to be asymptotically nonexpansive if there exists a sequence $\left\{k_{n}\right\}$ of positive real numbers with $k_{n} \geq 1$ and $\lim _{n \rightarrow+\infty} k_{n}=1$, such that $\left\|T^{n} x-T^{n} y\right\| \leq$ $k_{n}\|x-y\|$, for all $x, y \in E$ and $n \in N$.

(3) $T$ is said to be asymptotically quasi-nonexpansive if $F(T) \neq \varnothing$ and there exists a sequence $\left\{k_{n}\right\}$ of positive real numbers with $k_{n} \geq 1$ and $\lim _{n \rightarrow+\infty} k_{n}=1$ such that $\left\|T^{n} x-p\right\| \leq k_{n}\|x-p\|$, for all $x \in E, p \in F(T)$, and all $n \in N$.

(4) $T$ is said to be asymptotically nonexpansive type if

$$
\limsup _{n \rightarrow \infty}\left\{\sup _{x, y \in E}\left[\left\|T^{n} x-T^{n} y\right\|^{2}-\|x-y\|^{2}\right]\right\} \leq 0 .
$$


(5) $T$ is said to be asymptotically quasi-nonexpansive type if

$$
\limsup _{n \rightarrow \infty}\left\{\sup _{x \in E, y \in F(T)}\left[\left\|T^{n} x-p\right\|^{2}-\|x-p\|^{2}\right]\right\} \leq 0 .
$$

From the above definitions, it follows that if $F(T)$ is nonempty, quasi-nonexpensive mappings, asymptotically nonexpensive mappings, asymptotically quasi-nonexpensive mappings, and asymptotically nonexpensive type-mappings are all special cases of asymptotically quasi-nonexpensive-type mappings.

Definition 1.2 (see [2]). Let $T_{1}, T_{2}, T_{3}: E \rightarrow E$ be asymptotically quasi-nonexpansive-type mappings. Let $\left\{u_{n}\right\},\left\{v_{n}\right\},\left\{w_{n}\right\}$ be three given sequences in $E$ and let $x_{1}$ be a given point. Let $\left\{\alpha_{n}\right\},\left\{\beta_{n}\right\},\left\{\gamma_{n}\right\},\left\{\delta_{n}\right\},\left\{\eta_{n}\right\},\left\{\xi_{n}\right\}$ be sequences in $[0,1]$ satisfying the following conditions:

$$
\begin{aligned}
& \alpha_{n}+\gamma_{n} \leq 1, \quad \beta_{n}+\delta_{n} \leq 1, \quad \eta_{n}+\xi_{n} \leq 1, \\
& \sum_{n=1}^{\infty} \gamma_{n}<\infty, \quad \sum_{n=1}^{\infty} \delta_{n}<\infty, \quad \sum_{n=1}^{\infty} \xi_{n}<\infty .
\end{aligned}
$$

Then the sequence $\left\{x_{n}\right\} \subset E$ defined by

$$
\begin{array}{cc}
x_{n+1}=\left(1-\alpha_{n}-\gamma_{n}\right) x_{n}+\alpha_{n} T_{1}^{n} y_{n}+\gamma_{n} u_{n}, & n \geq 1, \\
y_{n}=\left(1-\beta_{n}-\delta_{n}\right) x_{n}+\beta_{n} T_{2}^{n} z_{n}+\delta_{n} v_{n}, & n \geq 1, \\
z_{n}=\left(1-\eta_{n}-\xi_{n}\right) x_{n}+\eta_{n} T_{3}^{n} x_{n}+\xi_{n} w_{n}, & n \geq 1,
\end{array}
$$

is called the three-step iterative sequence with mean errors of $T_{1}, T_{2}, T_{3}$.

Let $T_{1}, T_{2}, \ldots, T_{N}: E \rightarrow E$ be $N$ asymptotically quasi-nonexpansive-type mappings. Let $x_{1}$ be a given point. Then the sequence $\left\{x_{n}\right\}$ defined by

$$
\begin{aligned}
x_{n+1}= & \left(1-a_{n 1}-b_{n 1}\right) x_{n}+a_{n 1} T_{1}^{n} y_{n}+b_{n 1} u_{n 1}, \\
y_{n}= & \left(1-a_{n} 2-b_{n 2}\right) x_{n}+a_{n 2} T_{2}^{n} y_{n}+b_{n 2} u_{n} 2, \\
& \vdots \\
y_{n N-2}= & \left(1-a_{n N-1}-b_{n N-1}\right) x_{n}+a_{n N-1} T_{N-1}^{n} y_{n N-1}+b_{n N-1} u_{n N-1}, \\
y_{n N-1}= & \left(1-a_{n N}-b_{n}\right) x_{n}+a_{n} T_{N}^{n} x_{n}+b_{n} u_{n},
\end{aligned}
$$

is called the $N$-step iterative sequence with mean errors of $T_{1}, T_{2}, \ldots, T_{N}$, where $\left\{u_{n^{i}}\right\}_{n=1}^{\infty}$, $i=1,2, \ldots, N$, are $N$ sequences in $E,\left\{a_{n^{i}}\right\}_{n=1}^{\infty},\left\{b_{n^{i}}\right\}_{n=1}^{\infty}, i=1,2, \ldots, N$, are $N$ sequences in $[0,1]$ satisfying the following conditions:

$$
\begin{gathered}
a_{n^{i}}+b_{n^{i}} \leq 1, \quad n \leq 1, i=1,2, \ldots, N \\
\sum_{n=1}^{\infty} b_{n^{i}}<\infty, \quad i=1,2, \ldots, N .
\end{gathered}
$$


Petryshyn and Williamson [9] proved a sufficient and necessary condition for the Mann iterative sequences to converge to a fixed point for quasi-nonexpansive mappings. Ghosh and Debnath [5] extended the result of [9] and gave a sufficient and necessary condition for the Ishikawa iterative sequence to converge to a fixed point for quasinonexpansive mappings. Liu [6-8] extended the above results and proved some sufficient and necessary conditions for the Ishikawa iterative sequence or the Ishikawa iterative sequences with errors for asymptotically quasi-nonexpansive mappings to converge to a fixed point. Chidume et al. [4] obtained a strong convergence theorem to a fixed point of a family of nonself nonexpansive mappings in Banach spaces by an algorithm for nonselfmappings. Shahzad and Udomene [10] established necessary and sufficient conditions for the convergence of the Ishikawa-type iterative sequences involving two asymptotically quasi-nonexpansive mappings to a common fixed point of the mappings defined on a nonempty closed convex subset of a Banach space and a sufficient condition for the convergence of the Ishikawa-type iterative sequences involving two uniformly continuous asymptotically quasi-nonexpansive mappings to a common fixed point of the mappings defined on a nonempty closed convex subset of a uniformly convex Banach space. Alber [1] studied the approximating methods for finding the fixed points of asymptotically nonexpansive mappings.

Recently, Chang et al. [2] complement, improve, and perfect all the above results and obtained some necessary and sufficient conditions for the Ishikawa iterative sequence with mixed errors of asymptotically quasi-nonexpansive-type mappings in Banach spaces to converge to a fixed point in Banach spaces. And also using the $N$-step iterative sequences (1.5), Chang et al. [3] proved the weak and strong convergence of finite steps iterative sequences with mean errors to a common fixed point for a finite family of asymptotically nonexpansive mappings.

The purpose of this paper is to study sufficient and necessary conditions for finitestep iterative sequences with mean errors for a finite family of asymptotically quasinonexpansive-type mappings in Banach spaces to converge to a common fixed point. Our result shows that [2, Condidtion (2.1) in Theorem 2.1] can be removed. The results present in this paper improve, extend, and perfect the recent ones announced by Petryshyn and Williamson [9], Ghost and Debnath [5], Liu [6, 7], Xu and Noor [12], Chang [2, 3], Shahzad et al. [4], Shahzad and Udomene [10], Chidume et al. [1], and all the others.

In order to prove our main results, we will need the following lemma.

Lemma 1.3 (see [11]). Let $\left\{a_{n}\right\},\left\{b_{n}\right\}$ be sequences of nonnegative real numbers satisfying the inequality

$$
a_{n+1} \leq a_{n}+b_{n}, \quad n \geq 1 .
$$

If $\sum_{n=1}^{\infty} b_{n}<\infty$, then $\lim _{n \rightarrow \infty} a_{n}$ exists.

\section{Main results}

Theorem 2.1. Let $E$ be a Banach space and $T_{i}: E \rightarrow E(i=1,2, \ldots, N)$ be $N$ asymptotically quasi-nonexpansive-type mappings with a nonempty fixed-point set $F(T)=\bigcap_{i=1}^{N} F\left(T_{i}\right)$, that 
is,

$$
\limsup _{n \rightarrow \infty}\left\{\sup _{x \in E, p \in F(T)}\left[\left\|T_{i}^{n} x-p\right\|^{2}-\|x-p\|^{2}\right]\right\} \leq 0, \quad i=1,2, \ldots, N
$$

Let $\left\{u_{n^{i}}\right\}$ be a bounded sequence in E. For any given point $x_{1}$ in $E$, generate the sequence $\left\{x_{n}\right\}$ defined by (1.5). If $\sum_{n=1}^{\infty} \alpha_{n^{i}}<\infty$, then sequence $\left\{x_{n}\right\}$ strongly converges to a common fixed point of $T_{i}(i=1,2, \ldots, N)$ if and only if $\liminf _{n \rightarrow \infty} d\left(x_{n}, F(T)\right)=0$, where $d(y, S)$ denotes the distance of $y$ to set $S$; that is, $d(y, S)=\inf _{s \in S}\|y-s\|$.

Proof. (1) For the sake of convenience, we prove the conclusion only for the case of $N=3$ and then the other cases can be proved by the same way. For the purpose, let $\alpha_{n}=a_{n^{1}}$, $\beta_{n}=a_{n^{2}}, \eta_{n}=a_{n^{3}}, \gamma_{n}=b_{n^{1}}, \delta_{n}=b_{n^{2}}, \xi_{n}=b_{n^{3}}$. Then we can consider the sequence $\left\{x_{n}\right\}$ defined by (1.4) and $\left\{u_{n}\right\},\left\{v_{n}\right\},\left\{w_{n}\right\}$ are bounded. For all $p \in F(T)$, let

$$
\begin{array}{ll}
M_{1}=\sup \left\{\left\|u_{n}-p\right\|\right\}: n \geq 1, & M_{2}=\sup \left\{\left\|v_{n}-p\right\|\right\}: n \geq 1, \\
M_{3}=\sup \left\{\left\|w_{n}-p\right\|\right\}: n \geq 1, \quad M=\max \left\{M_{i}: i=1,2,3\right\} .
\end{array}
$$

It follows from (2.1) that

$$
\begin{array}{r}
\limsup _{n \rightarrow \infty}\left\{\sup _{x \in E, p \in F(T)}\left[\left(\left\|T_{i}^{n} x-p\right\|-\|x-p\|\right)\left(\left\|T_{i}^{n} x+p\right\|-\|x-p\|\right)\right]\right\} \\
\quad=\limsup _{n \rightarrow \infty}\left\{\sup _{x \in E, p \in F(T)}\left[\left\|T_{i}^{n} x-p\right\|^{2}-\|x-p\|^{2}\right]\right\} \leq 0, \quad i=1,2,3 .
\end{array}
$$

Therefore we have

$$
\limsup _{n \rightarrow \infty}\left\{\sup _{x \in E, p \in F(T)}\left[\left\|T_{i}^{n} x-p\right\|-\|x-p\|\right]\right\} \leq 0, \quad i=1,2,3 .
$$

This implies that for any given $\epsilon>0$, there exists a positive integer $n_{0}$ such that for $n \geq n_{0}$, we have

$$
\sup _{x \in E, p \in F(T)}\left\{\left\|T_{i}^{n} x-p\right\|-\|x-p\|\right\}<\epsilon, \quad i=1,2,3
$$

Since $\left\{x_{n}\right\},\left\{y_{n}\right\},\left\{z_{n}\right\} \subset E$, we have

$$
\begin{array}{ll}
\left\|T_{1}^{n} y_{n}-p\right\|-\left\|y_{n}-p\right\|<\epsilon, & \forall p \in F(T), \forall n \geq n_{0}, \\
\left\|T_{2}^{n} z_{n}-p\right\|-\left\|z_{n}-p\right\|<\epsilon, & \forall p \in F(T), \forall n \geq n_{0}, \\
\left\|T_{3}^{n} x_{n}-p\right\|-\left\|x_{n}-p\right\|<\epsilon, & \forall p \in F(T), \forall n \geq n_{0} .
\end{array}
$$


Thus for any $p \in F(T)$, using (1.4) and (2.6), we have

$$
\begin{aligned}
\left\|x_{n+1}-p\right\|= & \left\|\left(1-\alpha_{n}-\gamma_{n}\right)\left(x_{n}-p\right)+\alpha_{n}\left(T_{1}^{n} y_{n}-p\right)+\gamma_{n}\left(u_{n}-p\right)\right\| \\
\leq & \left(1-\alpha_{n}-\lambda_{n}\right)\left\|x_{n}-p\right\|+\alpha_{n}\left(\left\|T_{1}^{n} y_{n}-p\right\|-\left\|y_{n}-p\right\|\right) \\
& +\alpha_{n}\left\|y_{n}-p\right\|+\gamma_{n}\left\|u_{n}-p\right\| \\
\leq & \left(1-\alpha_{n}-\lambda_{n}\right)\left\|x_{n}-p\right\|+\alpha_{n} \epsilon+\alpha_{n}\left\|y_{n}-p\right\|+\gamma_{n} M .
\end{aligned}
$$

Consider the third term in the right-hand side of (2.9), using (1.4) and (2.7), we have that

$$
\begin{aligned}
\left\|y_{n}-p\right\|= & \left\|\left(1-\beta_{n}-\delta_{n}\right)\left(x_{n}-p\right)+\beta_{n}\left(T_{2}^{n} z_{n}-p\right)+\delta_{n}\left(v_{n}-p\right)\right\| \\
\leq & \left(1-\beta_{n}-\delta_{n}\right)\left\|x_{n}-p\right\|+\beta_{n}\left(\left\|T_{2}^{n} z_{n}-p\right\|-\left\|z_{n}-p\right\|\right) \\
& +\beta_{n}\left\|z_{n}-p\right\|+\delta_{n}\left\|v_{n}-p\right\| \\
\leq & \left(1-\beta_{n}-\delta_{n}\right)\left\|x_{n}-p\right\|+\beta_{n} \epsilon+\beta_{n}\left\|z_{n}-p\right\|+\delta_{n} M .
\end{aligned}
$$

Consider the third term in the right-hand side of (2.10), using (1.4) and (2.8), we have that

$$
\begin{aligned}
\left\|z_{n}-p\right\|= & \left\|\left(1-\eta_{n}-\xi_{n}\right)\left(x_{n}-p\right)+\eta_{n}\left(T_{3}^{n} x_{n}-p\right)+\xi_{n}\left(w_{n}-p\right)\right\| \\
\leq & \left(1-\eta_{n}-\xi_{n}\right)\left\|x_{n}-p\right\|+\eta_{n}\left(\left\|T_{3}^{n} x_{n}-p\right\|-\left\|x_{n}-p\right\|\right) \\
& +\eta_{n}\left\|x_{n}-p\right\|+\xi_{n}\left\|w_{n}-p\right\| \\
\leq & \left(1-\xi_{n}\right)\left\|x_{n}-p\right\|+\eta_{n} \epsilon+\xi_{n} M .
\end{aligned}
$$

Substituting (2.11) into (2.10) and simplifying, we have

$$
\left\|y_{n}-p\right\| \leq\left(1-\beta_{n} \xi_{n}-\delta_{n}\right)\left\|x_{n}-p\right\|+\beta_{n} \epsilon\left(1+\eta_{n}\right)+\beta_{n} \xi_{n} M+\delta_{n} M .
$$

Substituting (2.12) into (2.9) and simplifying, we have

$$
\begin{aligned}
\left\|x_{n+1}-p\right\| \leq & \left(1-\gamma_{n}-\alpha_{n} \beta_{n} \xi_{n}-\alpha_{n} \delta_{n}\right)\left\|x_{n}-p\right\|+\alpha_{n} \epsilon+\alpha_{n} \beta_{n} \epsilon\left(1+\eta_{n}\right) \\
& +\alpha_{n} \delta_{n} M+\alpha_{n} \beta_{n} \xi_{n} M+\gamma_{n} M \\
\leq & \left\|x_{n}-p\right\|+\alpha_{n}\left(1+\beta_{n}+\beta_{n} \eta_{n}\right) \epsilon+\left(\gamma_{n}+\delta_{n}+\xi_{n}\right) M \\
\leq & \left\|x_{n}-p\right\|+3 \alpha_{n} \epsilon+\left(\gamma_{n}+\delta_{n}+\xi_{n}\right) M .
\end{aligned}
$$

Let $A_{n}=3 \alpha_{n} \epsilon+\left(\gamma_{n}+\delta_{n}+\xi_{n}\right) M$. Then $A_{n} \geq 0$. It follows from (1.3) and $\sum_{n=1}^{\infty} \alpha_{n^{i}}<\infty$ that $\sum_{n=1}^{\infty} A_{n}<\infty$. Then by (2.13), we have

$$
\left\|x_{n+1}-p\right\| \leq\left\|x_{n}-p\right\|+A_{n} .
$$

It follows from (2.14) and $\sum_{n=1}^{\infty} A_{n}<\infty$ that

$$
d\left(x_{n+1}, F(T)\right) \leq d\left(x_{n}, F(T)\right)+A_{n} .
$$


By Lemma 1.3, we know that $\lim _{n \rightarrow \infty} d\left(x_{n}, F(T)\right)$ exists. Because $\liminf _{n \rightarrow \infty} d\left(x_{n}, F(T)\right)=$ 0 , then we have

$$
\lim _{n \rightarrow \infty} d\left(x_{n}, F(T)\right)=0 .
$$

Next we prove that $\left\{x_{n}\right\}$ is a Cauchy sequence in $E$.

It follows from (2.14) that for any $m \geq 1$, for all $n \geq n_{0}$, for all $p \in F(T)$,

$$
\begin{aligned}
\left\|x_{n+m}-p\right\| & \leq\left\|x_{n+m-1}-p\right\|+A_{n+m-1} \\
& \leq\left\|x_{n+m-2}-p\right\|+\left(A_{n+m-1}+A_{n+m-2}\right) \\
& \leq \cdots \leq\left\|x_{n}-p\right\|+\sum_{k=n}^{n+m-1} A_{k} .
\end{aligned}
$$

So by (2.17), we have

$$
\left\|x_{n+m}-x_{n}\right\| \leq\left\|x_{n+m}-p\right\|+\left\|x_{n}-p\right\| \leq 2\left\|x_{n}-p\right\|+\sum_{k=n}^{\infty} A_{k} .
$$

By the arbitrariness of $p \in F(T)$ and (2.18), we know that

$$
\left\|x_{n+m}-x_{n}\right\| \leq 2 d\left(x_{n}, F(T)\right)+\sum_{k=n}^{\infty} A_{k}, \quad \forall n \geq n_{0} .
$$

For any given $\bar{\epsilon}>0$, there exists a positive integer $n_{1} \geq n_{0}$ such that for any $n \geq n_{1}$, $d\left(x_{n}, F(T)\right)<\bar{\epsilon} / 4$ and $\sum_{k=n}^{\infty} A_{k}<\bar{\epsilon} / 2$. Thus when $n \geq n_{1},\left\|x_{n+m}-x_{n}\right\|<\bar{\epsilon}$. So we have that

$$
\lim _{n \rightarrow \infty}\left\|x_{n+m}-x_{n}\right\|=0 .
$$

This implies that $\left\{x_{n}\right\}$ is a Cauchy sequence in $E$. Since $E$ is complete, there exists a $p^{*} \in E$ such that $x_{n} \rightarrow p^{*}$ as $n \rightarrow \infty$.

Now we have to prove that $p^{*}$ is a common fixed point of $T_{i}, i=1,2, \ldots, N$, that is, $p^{*} \in F(T)$.

By contradiction, we assume that $p^{*}$ is not in $F(T)$. Since $F(T)$ is closed in Banach spaces, $d\left(p^{*}, F(T)\right)>0$. So for all $p \in F(T)$, we have

$$
\left\|p^{*}-p\right\| \leq\left\|p^{*}-x_{n}\right\|+\left\|x_{n}-p\right\| .
$$

By the arbitrary of $p \in F(T)$, we know that

$$
d\left(p^{*}, F(T)\right) \leq\left\|p^{*}-x_{n}\right\|+d\left(x_{n}, F(T)\right) .
$$

By (2.16), above inequality and $x_{n} \rightarrow p^{*}$ as $n \rightarrow \infty$, we have

$$
d\left(p^{*}, F(T)\right)=0
$$

which contracts $d\left(p^{*}, F(T)\right)>0$. This completes the proof of Theorem 2.1. 
Corollary 2.2. Suppose the conditions in Theorem 2.1 are satisfied. Then the N-step iterative sequence $\left\{x_{n}\right\}$ generated by (1.5) converges to a common fixed point $p \in E$ if and only if there exists a subsequence $\left\{x_{n_{j}}\right\}$ of $\left\{x_{n}\right\}$ which converges to $p$.

Theorem 2.3. Let $E$ be a Banach space and let $T_{i}: E \rightarrow E(i=1,2, \ldots, N)$ be $N$ asymptotically quasi-nonexpansive mappings with a nonempty fixed-point set $F(T)=\bigcap_{i=1}^{N} F\left(T_{i}\right)$. Let $\left\{u_{n^{i}}\right\}$ be a bounded sequence in $E$. For any given point $x_{1}$ in $E$, generate the sequence $\left\{x_{n}\right\}$ by (1.5). If $\sum_{n=1}^{\infty} \alpha_{n^{i}}<\infty$, then sequence $\left\{x_{n}\right\}$ strongly converges to a common fixed point of $T_{i}$ $(i=1,2, \ldots, N)$ if and only if $\liminf _{n \rightarrow \infty} d\left(x_{n}, F(T)\right)=0$, where $d(y, S)$ denotes the distance of $y$ to set $S$.

Proof. Since $T_{i}$ are asymptotically quasi-nonexpansive mappings with a nonempty fixedpoint set $F(T)=\bigcap_{i=1}^{N} F\left(T_{i}\right)$, by [3, Proposition 1] or [13], we know that there must exist a sequence $\left\{k_{n}\right\} \subset[1, \infty)$ with $k_{n} \rightarrow 1$ as $n \rightarrow \infty$ such that

$$
\left\|T_{i}^{n} x-p\right\| \leq k_{n}\|x-p\|, \quad \forall p \in F(T), \forall x \in E, n \geq 1 .
$$

This implies that

$$
\left\|T_{i}^{n} x-p\right\|^{2}-\left(k_{n}\right)^{2}\|x-p\|^{2} \leq 0, \quad \forall p \in F(T), \forall x \in E, n \geq 1 .
$$

Therefore we have

$$
\limsup _{n \rightarrow \infty}\left\{\sup _{x \in D, p \in F(T)}\left[\left\|T_{i}^{n} x-p\right\|^{2}-\|x-p\|^{2}\right]\right\} \leq 0, \quad i=1,2, \ldots, N .
$$

This implies that $T_{i}, i=1,2, \ldots, N$, are $N$ asymptotically quasi-nonexpansive-type mappings with a nonempty fixed-point set $F(T)=\bigcap_{i=1}^{N} F\left(T_{i}\right)$. Theorem 2.3 can be proved by Theorem 2.1 immediately.

Theorem 2.4. Let $E$ be a Banach space and let $T_{i}: E \rightarrow E(i=1,2, \ldots, N)$ be $N$ asymptotically nonexpansive mappings with a nonempty fixed-point set $F(T)=\bigcap_{i=1}^{N} F\left(T_{i}\right)$. Let $\left\{u_{n^{i}}\right\}$ be a bounded sequence in E. For any given point $x_{1}$ in $E$, generate the sequence $\left\{x_{n}\right\}$ by (1.5). If $\sum_{n=1}^{\infty} \alpha_{n^{i}}<\infty$, then sequence $\left\{x_{n}\right\}$ strongly converges to a common fixed point of $T_{i}$ $(i=1,2, \ldots, N)$ if and only if $\liminf _{n \rightarrow \infty} d\left(x_{n}, F(T)\right)=0$.

Remarks 2.5. We would like to point out that Theorems 2.1, 2.3, and 2.4 generalize and improve the corresponding results of Petryshyn and Williamson [9], Ghost and Debnath [5], Liu [6, 7], and $\mathrm{Xu}$ and Noor [12]. These theorems especially improve Chang's results [2] in the following aspects.

(1) We removed the condition (2.1) "there exists constant $L>0$ and $\alpha>0$ such that $\|T x-p\| \leq L\|x-p\|^{\alpha}, \forall x \in E, \forall p \in F(T)$ ” in [2].

(2) "The Ishikawa iterative sequence with mixed errors" is extended to $N$-step iterative sequence with mean errors, and so we obtain the common fixed point of $N$ asymptotically nonexpansive-type mappings.

\section{Acknowledgment}

This work was supported by the National Science Foundation of China. 


\section{References}

[1] Ya. I. Alber, C. E. Chidume, and H. Zegeye, Approximating fixed points of total asymptotically nonexpansive mappings, Fixed Point Theory \& Applications 2006 (2006), Article ID 10673, 20 pages.

[2] S.-S. Chang, J. K. Kim, and S. M. Kang, Approximating fixed points of asymptotically quasinonexpansive type mappings by the Ishikawa iterative sequences with mixed errors, Dynamic Systems and Applications 13 (2004), no. 2, 179-186.

[3] S.-S. Chang, H. W. J. Lee, and Y. J. Cho, On the convergence of finite steps iterative sequences for asymptotically nonexpansive mappings, Dynamics of Continuous, Discrete \& Impulsive Systems. Series A. Mathematical Analysis 11 (2004), no. 4, 589-600.

[4] C. E. Chidume, H. Zegeye, and N. Shahzad, Convergence theorems for a common fixed point of a finite family of nonself nonexpansive mappings, Fixed Point Theory \& Applications 2005 (2005), no. 2, 233-241.

[5] M. K. Ghosh and L. Debnath, Convergence of Ishikawa iterates of quasi-nonexpansive mappings, Journal of Mathematical Analysis and Applications 207 (1997), no. 1, 96-103.

[6] Q. H. Liu, Iterative sequences for asymptotically quasi-nonexpansive mappings, Journal of Mathematical Analysis and Applications 259 (2001), no. 1, 1-7.

[7] __ Iterative sequences for asymptotically quasi-nonexpansive mappings with error member, Journal of Mathematical Analysis and Applications 259 (2001), no. 1, 18-24.

[8] _ Iteration sequences for asymptotically quasi-nonexpansive mapping with an error member of uniform convex Banach space, Journal of Mathematical Analysis and Applications 266 (2002), no. 2, 468-471.

[9] W. V. Petryshyn and T. E. Williamson Jr., Strong and weak convergence of the sequence of successive approximations for quasi-nonexpansive mappings, Journal of Mathematical Analysis and Applications 43 (1973), 459-497.

[10] N. Shahzad and A. Udomene, Approximating common fixed points of two asymptotically quasinonexpansive mappings in Banach spaces, Fixed Point Theory \& Applications 2006 (2006), Article ID 18909,10 pages.

[11] K.-K. Tan and H. K. Xu, Approximating fixed points of nonexpansive mappings by the Ishikawa iteration process, Journal of Mathematical Analysis and Applications 178 (1993), no. 2, 301-308.

[12] B. L. Xu and M. A. Noor, Fixed-point iterations for asymptotically nonexpansive mappings in Banach spaces, Journal of Mathematical Analysis and Applications 267 (2002), no. 2, 444-453.

[13] Y. Y. Zhou and S.-S. Chang, Convergence of implicit iteration process for a finite family of asymptotically nonexpansive mappings in Banach spaces, Numerical Functional Analysis and Optimization 23 (2002), no. 7-8, 911-921.

Jing Quan: Department of Mathematics, Chongqing Normal University, Chongqing 400047, China E-mail address: quanjingcq@163.com

Shih-Sen Chang: Department of Mathematics, Yibin University, Yibin, Sichuan 644007, China E-mail address: sszhang_1@yahoo.com.cn

Xian Jun Long: Department of Mathematics, Chongqing Normal University, Chongqing 400047, China

E-mail addresses: longxj12345@163.com; xianjunlong@hotmail.com 